\title{
THE INFLUENCE OF IRANIAN ISLAMIC ARCHITECTURE ON THE JEWISH HOUSE (WEST SĀBĀT HOUSE) OF BAM CITADEL
}

\author{
J. ROUHI, A. AVETA \& B.G. MARINO \\ Department of Architecture, University of Naples Federico II, Italy.
}

\begin{abstract}
Iranian Islamic architecture beyond the evident typology is formed through a conceptual framework, which has a great deal of importance to show suitable and compatible-with-climate designs. Specifically in the hot and arid regions of Iran, vernacular architecture has frequently intimated the formation of cities and the architectural combinations. The ancient city of Bam by itself is a field, the origin of which can be considered as one of the first foci for the organization of civilization in the hot and arid environments of Iran throughout history, which shows traces of architecture that organizes spaces in such a way that they function as a medium to emphasize the relevance of human lifestyle. This article describes the history of Jewish House briefly, wherein the mansion was one of the loftiest traditional houses in Bam Citadel, and later classifies the effects of natural and cultural criteria in its climate-compatible architectural design. In fact, we can get a complete resource about the norms of Iranian Islamic architecture on the traditional Jewish House and the qualities and functions that encouraged this family tendency for utilizing Iranian Islamic architecture in their residence.

Keywords: Bam Citadel, Hot and arid climate, Iranian Islamic Architecture, Iranian Traditional buildings, Jewish House.
\end{abstract}

\section{INTRODUCTION}

The word 'Iranian Islamic architecture' is derived from beliefs that brought in Iranian architecture when Islam was introduced around the 7th century. The flourishing of Iranian Islamic architecture is the result of development from various civilizations through a straight line of evolution over centuries by drawing ideas that constitute post-Islamic architecture. Since every Islamic country has its own form of architecture and style [1], Iranian architecture gave rise to a great upheaval in Islamic architecture and laid the foundations for Islamic architecture all over the world. In general terms, Iranian artists adjusted to the needs of Arabic Islamic culture, which was in turn influenced by Iranian traditions [2]. Meanwhile, Iranian architecture did not lose its identity in confrontation with the ethics of Islam, but Iranian architects re-created the buildings based on local culture and civilization with adaption to the Islamic point of view [3].

Architecture and culture are two relevant issues that introduce the identity of a society. The architecture domain can determine any civilization and represent itself as a preface to declare the cultural values of a society. Therefore, from the beginning all architectural and vernacular forms were used to improve the quality of living. As a result, architecture has to follow any kind of cultural and social transformation and rapidly adjust itself to it. Meanwhile, since the Muslim cultures throughout Islamic history were inspired by spiritual essence, Islamic architects have considered climate and environment as one of the most important factors that generate a correlation between the spiritual demands of the inhabitants, the environment

This paper is part of the Proceedings of the International Conference on Islamic Heritage Architecture and Art (Islamic Heritage Architecture 2016)

www.witconferences.com 
and the climate, and applied these factors to create a formal form [4]. Accordingly, Iranian architecture in Iranian territories with hot and arid climate possessed its own specifications combined with Islamic belief criteria.

Iran is one of the unique countries in the world with different climates in different regions. This environmental characteristic promoted Iranian traditional architectures to use efficient natural climatic designs in order to cope with the difficult weather conditions. In Iran the hot and arid region encompasses the majority of the central Iranian plateau [5], where lower levels of humidity and the lack of clouds result in extreme temperature fluctuations during both day and night [6].

The Citadel of Bam (Arg-e Bam) as an outstanding example of a fortified medieval town is located in this weather condition on the southern edge of the Iranian high plateau, Kerman Province, Iran (Fig. 1). This ancient citadel is considered as the largest extant adobe-mud brick complex in the world, which has kept its traditional architecture in the Iranian desert environment not only up to the day they were severely damaged by the 2003 Bam earthquake, but even today. This ancient city, since being intruded during centuries for its strategic location in the Silk Road, can be considered as one of the first foci for the organization of civilization in a multicultural society involving different religions such as Zoroastrian, Jewish, Islamic, Christian. Based on available evidence and ruins in Bam Citadel, it can be perceived that most of the symbolic features of traditional buildings are inspired by natural and cultural needs and occupant requirements.

There is a need to question the principles of designing traditional buildings in Bam Citadel from the point of culture, religion and tradition along with environmental and climatic conditions. To meet this need one key example of traditional houses in the public space of Bam Citadel will be investigated. As a brief introduction, Jewish House or West Sābāt House is one of the oldest traditional houses in Bam Citadel and based on reports of the cultural heritage organization of Iran, it probably belonged to a Jewish family, which has evolved since the pre-Islamic times, i.e. Parthian, Sasanian and Qajar periods [7]. In the architecture of Jewish House more than a few architectonic elements, with those illustrating various strategies, have

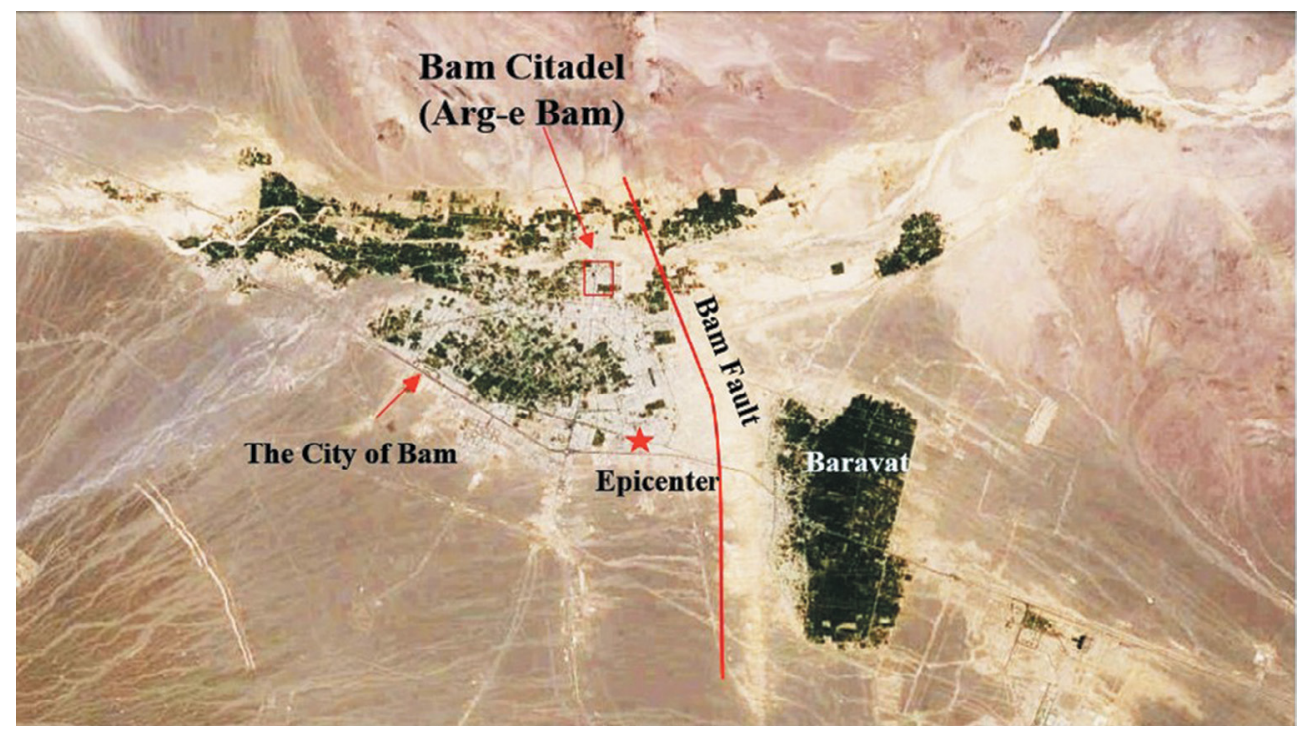

Figure 1: The location of Bam Citadel in the city of Bam. 
been developed with major environmental and cultural potential. In spite of the review on such traditional experiences, not only can we address the Islamic thoughts that merged in Iranian architecture, but also we can discover many mysterious tricks that Iranian architects utilized to create meaningful spaces.

\section{GENERAL VIEWS OF JEWISH HOUSE (WEST SĀBĀT HOUSE) FROM PAST TO PRESENT}

The city of Bam since ancient times is known for its production of silk and cotton garments, the name Bam being associated with the 'burst of the worm' (silk worm). Ebn Hawqal enlarges upon this statement, mentioning that the material for the fabric appears to grow in the neighbourhood of Bam. He writes: 'From their cotton, splendid high-quality and longlasting garments are made' (pp. 73-80) [8]. Probably the collection of mentioned goods by Jewish families who have lived till 1978 in Bam was being accomplished through Spice Road, sidetrack silk Road, all over the world [7].

One of the loftiest buildings in Bam Citadel that belongs to one of the Jewish families is Jewish House or West Sābāt House (Fig. 2). This house is located in the main residential quarters of the historic town, along the Jewish passageway (Sābāt-e Johudhā in Persian) to the east of the stables and the extreme north of the town before the second fortified wall almost opposite of (in front of) the second gateway.

Jewish House is built in the traditional technique by combining mud layers (chineh), sundried mud bricks (khesht) along with chalk decoration, chalk trim, sieved straw and mud and straw as predominate coating material. Jewish House consists of a relatively large house with a central courtyard flanked by two series of rooms in two floors [8]. Its western part is the oldest part [7] and its southern part grabs viewer's attention by a row of five wind towers and charming balconies. This traditional residential house was inscribed on the National Heritage List of Iran with registration No. 9568, on 18 August 2003, and is legally under the State's protection and supervision of the Iranian Cultural Heritage Organization.

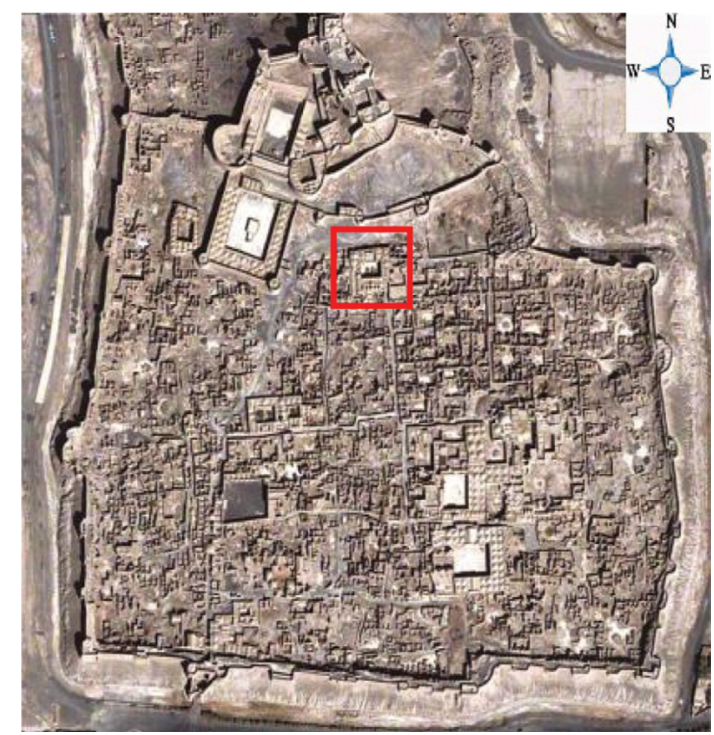

Figure 2: The location of Jewish House in Bam Citadel. 
Despite the results of Dr. Tayyari's annual report from 1994 to 1999 in order to restore and renovate the Jewish House, the 2003 Bam earthquake severely damaged it. So far, after the earthquake, due to the lack of restoration plans and budget constraints, expect debris removal and some preservative measures, no significant restoration has been carried out (Fig. 3).

\subsection{The influence of culture on architecture}

Since the residents' living environment is strongly related to their cultural, personal and social identity $[9,10]$, the development of Islam provided knowledge especially in relation to guidance and direction in life according to religious principles and obligations [11]. Iranian traditional architecture defines its architectural principles from an explicit definition of the public and private spaces within a spatial hierarchy in accordance with Islamic thoughts.

\subsubsection{Privacy}

One of the most important principles considered in Iranian traditional architecture, especially after Islam, is the principle of privacy [12]. Indeed, the influence of Islamic culture on Iranian architecture portrays excellent evidence of how spatial organization in housing is formed by the values of privacy. The interior spaces in Iranian Islamic architecture are separated from the exterior space by a wall. Behind of the door there is only a projected part named narthex, where guests wait till the host opens the door. This strategy was used to respect the privacy of males and females in order to avoid unnecessary communication in social relationship. This is the influence of Islamic culture in Iranian architecture.

Following the subject of privacy, there is another set-up of two metal handles on the door: one handle with soft sound is shaped as a ring for use by females and another with rough sound is shaped as a hammer for use by males; through the sound of each handle the residents could easily find out the gender of their guest (Fig. 4).

\subsubsection{Introversion}

As already mentioned some concepts in Iranian Islamic architecture seem to be derived from Islamic beliefs and also the vernacular architecture. Introversion is one of the concepts that values the private life and its sanctity. In the hot and arid climate of Iran, this introversion has shown itself in terms of a central courtyard as a space with an independent, central, internal and open geometric design (Fig. 5).

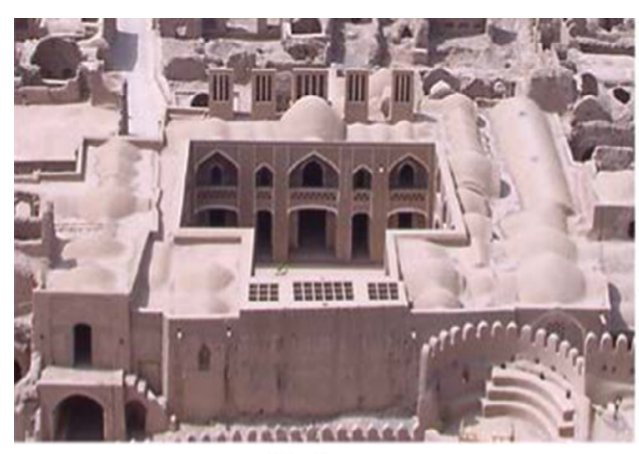

Before

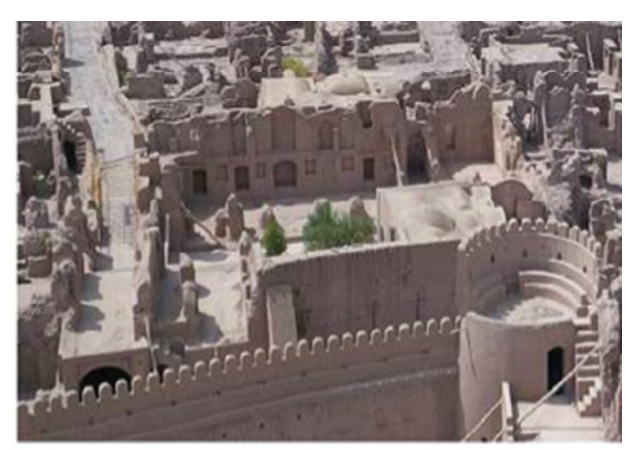

Current

Figure 3: View of Jewish House before the earthquake (photo by Yashuda, 2001) and its current situation (photo by Rouhi 2015). 


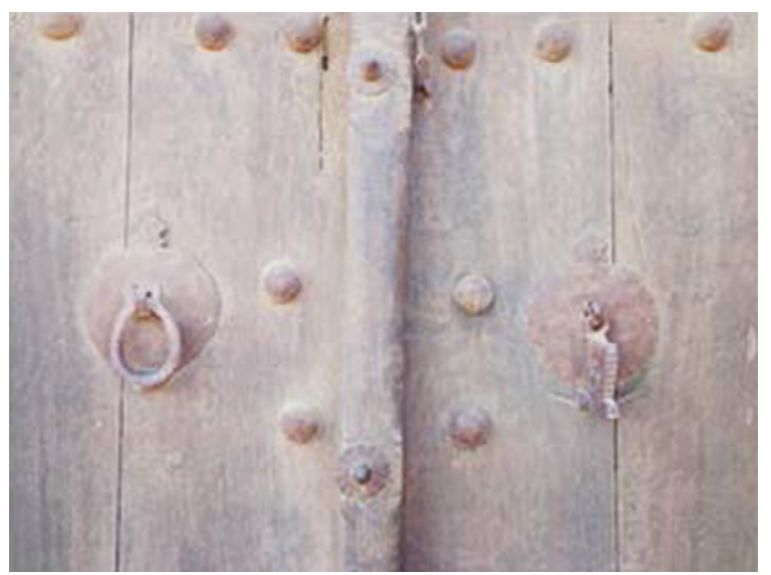

Figure 4: Metal handles of a door opener in Jewish House. Photo by Rouhi, 2015.

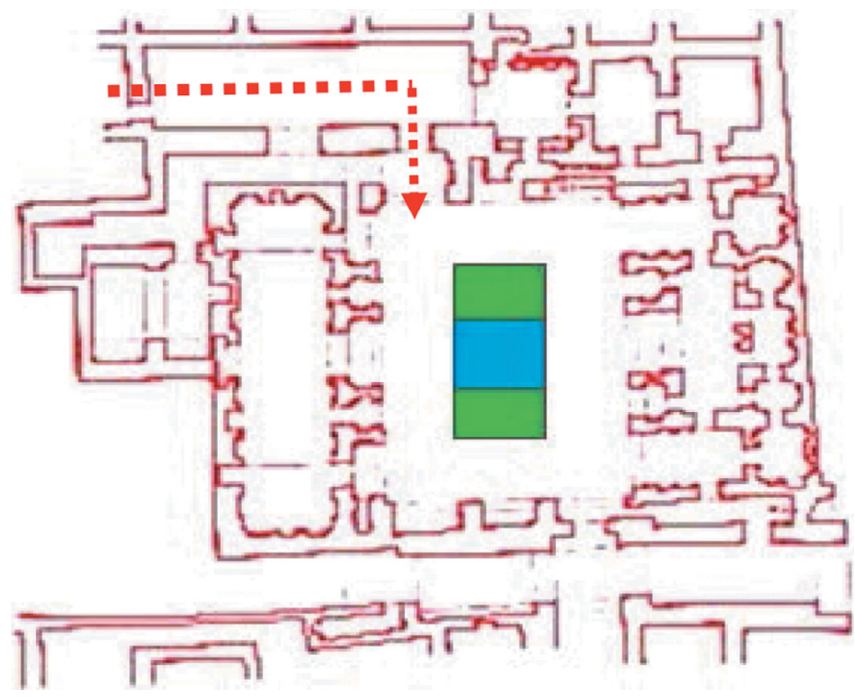

Figure 5: Introversion of Jewish House around a central courtyard.

\subsection{The relationship of architecture and nature}

Moradi in his report 'comparative plan of Kerman Cultural Historical Axis' [13] has considered nine principles in the formation of Kerman traditional architecture, which can be generalized to the city of Bam as one of the city of Kerman Province. These include (1) reflection of the heat of the sun; (2) proper directions of buildings; (3) prevention of penetration of very hot and cold weather; (4) protection of people in the complex; (5) providing desirable and cool weather; (6) making use of evaporative cooling; (7) creation of desirable weather in the yard; (8) optimum use of sun's heat; and (9) keeping the room cold in summer and hot in winter.

In order to meet the aforementioned principles, native architects of Bam have achieved an ideal climate-responsive design as a consequence of experience-based knowledge, which they have acquired through trial and error over time, some of which will be investigated below. 


\subsubsection{Material}

A city in a desert climate is basically vulnerable to desert expansion and desertification and also to the harsh climate of the desert. This phenomenon prompted designers and architects to use natural climatic approaches in order to adapt to these harsh conditions [14]. Available building materials dictate major forms in traditional Iranian architecture. Heavy clays, readily available at various places throughout the plateau, have encouraged the development of the most primitive of all building techniques, moulded mud, compressed as solidly as possible and allowed to dry. This technique, used in Iran from ancient times, has never been completely abandoned. The abundance of heavy plastic earth, in conjunction with a tenacious lime mortar, also facilitated the development and use of brick [15]. As Master Pirnia [16, p. 24] noted, "clay is an available building material in Iran that dictated major forms in traditional Iranian architecture. Heavy clays have encouraged the development of the most primitive of all building techniques. Brick layers compressed solidly molded mud and allowed it to dry. Tenacious lime mortar also eased the development and use of brick'.

Adobe-mud brick structures serve as a significant heat reservoir due to the thermal properties inherent in the massive walls and roofs. In climates typified by extreme temperature fluctuations during both day and night, the high thermal mass of adobe mediates the living space temperature. The body of massive adobe-mud brick structures after sunset, when the temperature drops rapidly, will continue to transfer heat to the interior spaces of the house for several hours due to the time-lag effect.

In addition, the construction practice of adobe structure is naturally simple and does not require any special energy resources. Skilled technicians (engineers and architects) are generally not involved in this type of construction, hence the terms 'non-engineered construction' and 'informal construction' (Fig. 6) [17].

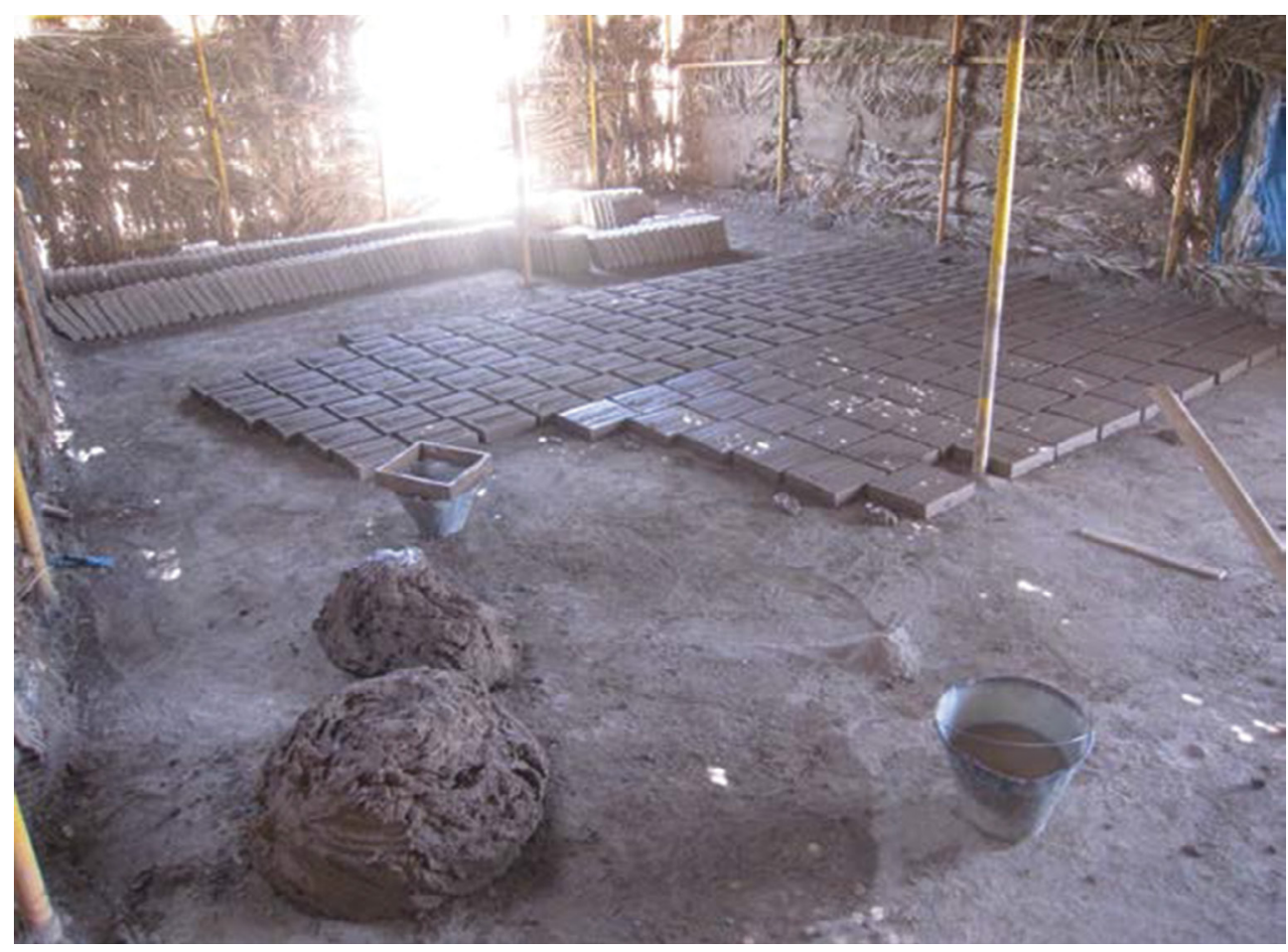

Figure 6: Adobe-mud brick production at Bam Citadel. Photo by Rouhi, 2015. 


\subsubsection{Building orientation}

The topography is a critical parameter that determines the architecture of buildings in the hot and arid climatic zone of Iran. In Bam, traditional residential houses are almost oriented in two distinct directions. Owing to the characteristics of sun (at all seasons) and wind (during the hot season) in this region, the North-South and West-East are suitable positions for building orientation in order to provide residents a comfortable living space throughout the year even under severe undesirable weather conditions.

\subsubsection{Building plan}

Iranian traditional architecture in the hot and arid climate is generally based on a symmetrical layout and four-sided design towards the four geographical directions (north, south, east and west) to reduce the absorption of sun's radiation in harsh weather conditions. While the absorption of sun radiation increases in one direction, occupants could change their rooms according to usage for daily activities.

\subsubsection{Courtyard}

In Iran, courtyard houses are the most prominent types of houses [18]. The courtyard as the heart of the house in the spatial, social and environmental context fulfills several functions for the residents and its users in the hot and arid region. This part with its inherent complements in a rectangular plot can provide security, privacy and comfort within the house. The central courtyard consisting of a little pond and garden with trees, shrubs and flowers not only links different areas of the house inside a beautiful space but also increases the relative humidity, natural lighting and ventilation (Fig. 7).

\subsubsection{Iwan}

Iwans were a trademark of the Sassanid architecture of Persia (224-651 AD), which then found their way into the Arab and Islamic architecture and started developing in the 7th century AD ('Dictionary of Islamic architecture: Ivvan'). An iwan is defined as a rectangular hall or space, usually vaulted, walled on three sides, with one end directly opening on to a central

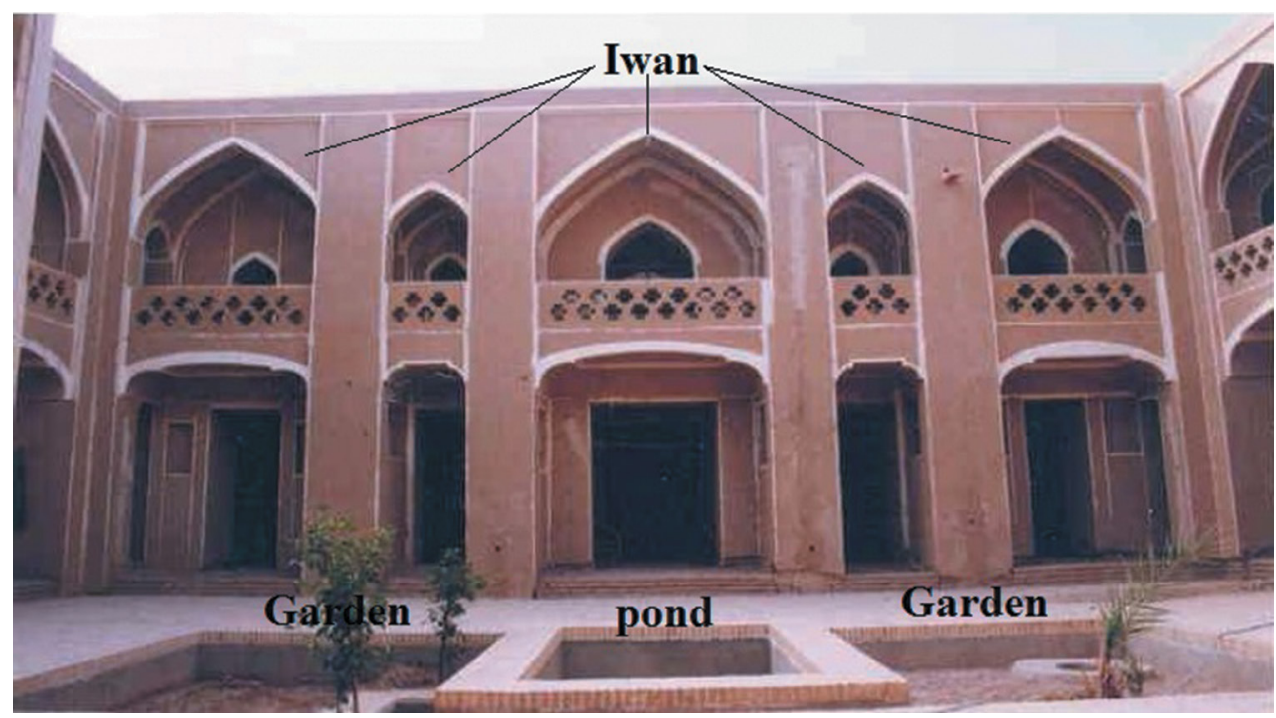

Figure 7: Central courtyard and iwans in Jewish House. Photo by ICHO. 
courtyard. The design objective of an iwan or semi-open areas is to provide shade and cool living spaces during the day [12].

\subsubsection{Curved roof}

The best form of architecture is the one that loses the least volume of heat during winter and absorbs the greatest volume of coldness during summer. Apart from thermal mass (delay in the heat transfer) and thermal resistance of adobe structures, the curved roof as a passive cooling system provides further advantages to create a thermal equilibrium inside the house in a desert environment.

From a geometric point of view, the impact angle of the sunbeam on curved roof due to having convex and unbalanced surface is different from one point to another, and a part of it always remains in shade during the day.

Meanwhile, the external surface area of a curved roof is almost three times larger than its internal surface area so that at the time of heat transfer the lower rates of heat will be attracted by the internal surface.

As a consequence of the advantages of curved roofs, a domed roof is always exposed by wind blown in different directions, which is why if a hole is present at the apex of a domed or cylindrical roof, it takes the favourable wind and conducts airflows from outside into the main rooms (Fig. 8).

\subsubsection{Wind tower}

A wind tower is a centuries-old Persian architectural element that takes advantage of natural ventilation in buildings. This traditional Persian-influenced architecture has been used for centuries in many countries of hot and arid and hot and humid climates, particularly throughout the Middle East. Evidence about the commander's house of Bam Citadel consisting of three adjacent wind towers, each in different directions, reveals that the existence of wind towers in Bam region belonged to the pre-Islamic era. According to the directions of the favourable winds, wind towers were constructed in various designs: uni-directional, bidirectional and multi-directional.

A typical wind tower consists of a tower with vertical wings at the top of the roof, with its arteries open in the direction of desirable winds and closed in the direction of undesirable winds and sandstorms. The function of a wind tower is that its vertical wings conduct cold air within the rooms while leading out the hot and pollutant air from inside the building (Fig. 9).

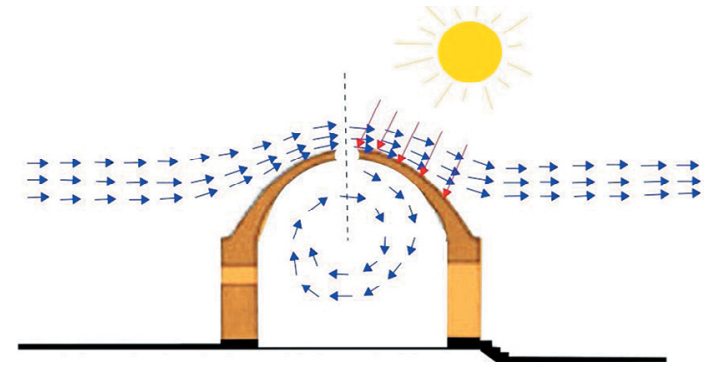

Figure 8: The effects of sun and wind on curved roofs, which are exposed to minimum sunbeam and maximum wind breeze. 


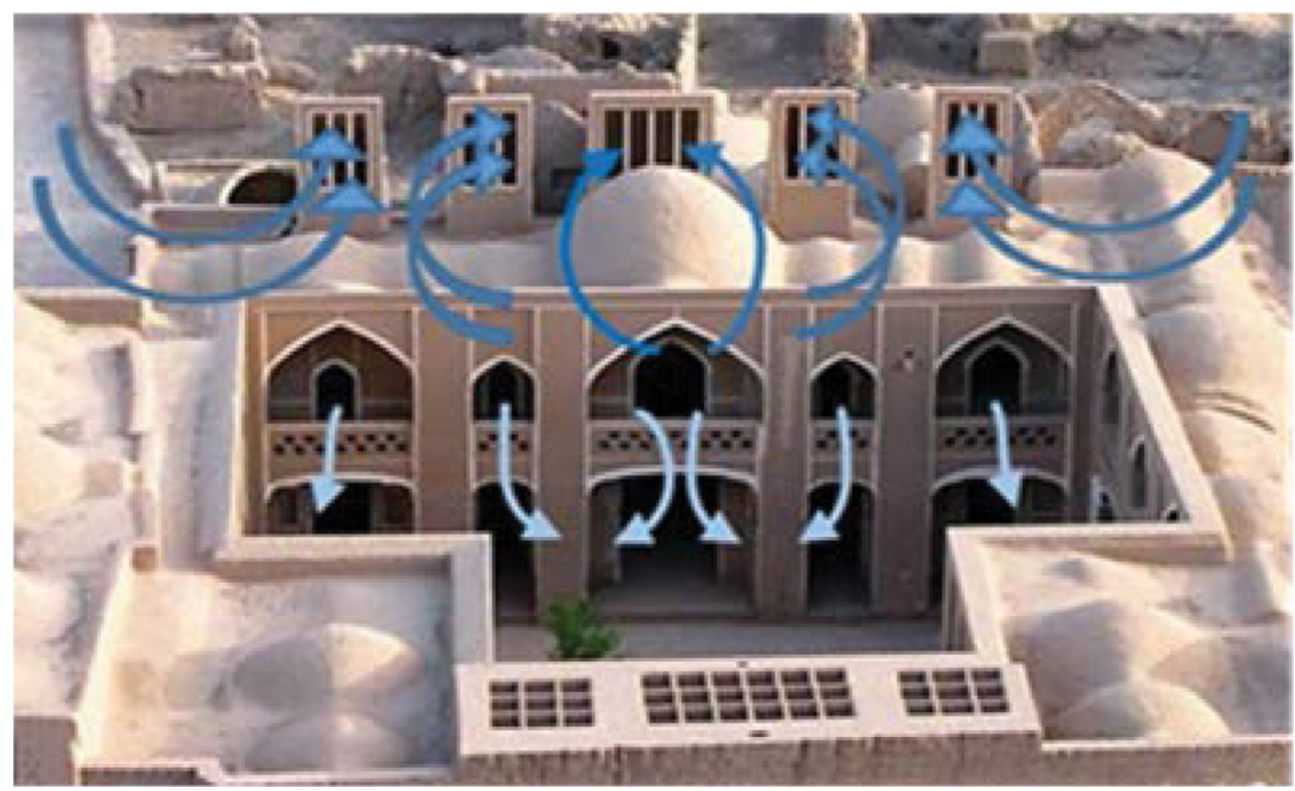

Figure 9: The quality of air ventilation by wind towers in Jewish house.

\section{CONCLUSION}

This article attempted to show the strengths of Iranian Islamic architecture in assimilation of forms, spaces and elements in such a way that a correlation is created between dominant parameters and a comfortable atmosphere is provided for its residents. Traditional residential buildings in Iranian Islamic architecture have been designed based on culture, religion, traditions and an ideal harmony with the climate of each region and lifestyles. In today's architecture the residential buildings are not designed as carefully as earlier times and unfortunately all of the past design strategies are being gradually ignored as the world's lifestyle has been changing quite fast. This fact should evoke contemporary architects to realize the principles of traditional architectures and achieve a comprehensive understanding of conditions in order to be able to respond to future requirements. As can be concluded from the consequences of the case study, there are various concepts in Iranian Islamic architecture that can simultaneously guarantee the security and convenience of people's lives in hot and arid weather condition. In an overview about history of traditional architecture of Iran as a country with a rich history and various climatic circumstances not only can clarify the unity and continuity of the Persian architecture, but also can create a new path forward to architects and designers to solve today's architecture deficiency.

\section{REFERENCES}

[1] Frankfort, H., The Art and Architecture of the Ancient Orient, Yale University Press, Pelican History of Art: New Haven, CT, 1996.

[2] Damadi, M., Characteristics of Islamic and Iranian architecture. International Journal of Advanced Research in Engineering and Applied Sciences, 9(2), pp. 1-13, 2013.

[3] Hosseini, B. \& Karimi, A.Z., A Brief Survey on the Principles of Iranian Islamic Architecture. Proceedings of the 2nd International Conference on Archi-Cultural 
Translations through the Silk Road, eds. iaSU2012 JAPAN Publication Committee, Mukogawa Women's University: Nishinomiya, Japan, pp. 318-323, 2012.

[4] Memarian, G. \& Sadoughi, A., Application of access graphs and home culture: examining factors relative to climate and privacy in Iranian houses. Scientific Research and Essays, 6(30), pp. 6350-6363, 2011. available at http://www.academicjournals.org/SRE

[5] Daniel, E.L. \& Mahdi, A.A., Culture and Customs of Iran, Greenwood Press: Westport, CT and London, 2006.

[6] Iranmanesh, N. \& Bigdeli, E., Climatic design \& low carbon city regarding the traditional experiences. Proceedings of the 45th International Congress on Climatic Design \& Low Carbon City, ISOCARP: Porto, Portugal, pp. 1-6, 2009.

[7] Tohidi, M., Argname. The Center of Kerman's Studies: Kerman, pp. 41-42, 2014. (in Persian)

[8] Bam and Its Cultural Landscape, whc.unesco.org/uploads/nominations/1208bis.pdf

[9] Dovey, K., Home and homelessness. Home Environments, 8(1), pp. 33-64, 1985. DOI: 10.1007/978-1-4899-2266-3_2.

[10] Proshansky, H.M., Fabian, A.K. \& Kaminoff, R., Place identity: Physical world socialization of the self. Journal of Environmental Psychology, 3(1), pp. 57-83, 1983. DOI: 10.1016/S0272-4944(83)80021-8.

[11] Seyfian, M.K. \& Mahmudi, M.R., Privacy in the Iran's traditional architecture. Journal of Identity of City, 1(1), pp. 3-14, 2007.

[12] Pirnia, M.K., The Islamic Architecture of Iran. Soroush Publications: Tehran, 2005. (in Persian)

[13] Moradi, M.A., Comparative Plan of Kerman Cultural-Historical Axis. Kerman Province Housing and City Planning General Office Press: Kerman, p. 75, 2002. (in Persian)

[14] Taleghani, M., Behboud, K.T. \& Heidari, S., Energy efficient architectural design strategies in hot-dry area of Iran: Kashan. Engineering Research, 15(2), pp. 85-91, 2010.

[15] Pope, A.U., Persian Architecture. George Braziller: New York, p. 9, 1965.

[16] Pirnia, M.K., Study of Styles in Iranian Architecture. Soroush Publications: Tehran, p. 24, 2005. (in Persian)

[17] Blondet, M., Villa Garcia M.G., Brzev, S. \& Rubiños, Á., Earthquake-Resistant Construction of Adobe Buildings: A Tutorial. EERI/IAEE World Architecture Housing Encyclopedia: Oakland, CA, p. 1, 2011.

[18] Moradi, A.M. \& Akhtarkavan, M., Sustainable in the hot, arid and sunny regions of Iran. Architect Engineering Special Issue, 19(6), pp. 21-29, 2008. 